\title{
Effects of Nanohydroxyapatite Incorporation into Glass Ionomer Cement (GIC)
}

\author{
Rishnnia Murugan $^{1}\left(\mathbb{D}\right.$, Farinawati Yazid ${ }^{2}\left(\mathbb{D}\right.$, Nurrul Shaqinah Nasruddin ${ }^{3}$ and Nur Najmi Mohamad Anuar ${ }^{1, *(\mathbb{D})}$ \\ 1 Programme of Biomedical Science, Center for Toxicology \& Health Risk Studies, Faculty of Health Sciences, \\ Universiti Kebangsaan, Kuala Lumpur 50300, Malaysia; rishnniabella1998@gmail.com \\ 2 Department of Family Oral Health, Faculty of Dentistry, Universiti Kebangsaan, \\ Kuala Lumpur 50300, Malaysia; drfarinawati@ukm.edu.my \\ 3 Department of Craniofacial Diagnostics and Biosciences, Faculty of Dentistry, Universiti Kebangsaan, \\ Kuala Lumpur 50300, Malaysia; shaqinah@ukm.edu.my \\ * Correspondence: nurnajmi@ukm.edu.my
}

check for updates

Citation: Murugan, R.; Yazid, F.; Nasruddin, N.S.; Anuar, N.N.M. Effects of Nanohydroxyapatite Incorporation into Glass Ionomer Cement (GIC). Minerals 2022, 12, 9. https: / / doi.org/10.3390/ $\min 12010009$

Academic Editors: Josy A. Osajima, Edson Cavalcanti da Silva Filho and Maria Gardennia Fonseca

Received: 11 October 2021 Accepted: 15 December 2021 Published: 22 December 2021

Publisher's Note: MDPI stays neutral with regard to jurisdictional claims in published maps and institutional affiliations.

Copyright: (c) 2021 by the authors. Licensee MDPI, Basel, Switzerland. This article is an open access article distributed under the terms and conditions of the Creative Commons Attribution (CC BY) license (https:// creativecommons.org/licenses/by/ $4.0 /)$.

\begin{abstract}
Glass ionomer cement (GIC) or polyalkenoate cement is a water-based cement that is commonly used in clinical dentistry procedures as a restorative material. It exhibits great properties such as fluoride-ion release, good biocompatibility, ease of use and great osteoconductive properties. However, GIC's low mechanical properties have become a major drawback, limiting the cement's usage, especially in high stress-bearing areas. Nanohydroxyapatite, which is a biologically active phosphate ceramic, is added as a specific filler into glass ionomer cement to improve its properties. In this review, it is shown that incorporating hydroxyapatite nanoparticles (nHA) into GIC has been proven to exhibit better physical properties, such as increasing the compressive strength and fracture toughness. It has also been shown that the addition of nanohydroxyapatite into GIC reduces cytotoxicity and microleakage, whilst heightening its fluoride ion release and antibacterial properties. This review aims to provide a brief overview of the recent studies elucidating their recommendations which are linked to the benefits of incorporating hydroxyapatite nanoparticles into glass ionomer cement.
\end{abstract}

Keywords: antibacterial property; cytotoxicity; fluoride-ion release; glass ionomer cement; nanohydroxyapatite

\section{Introduction}

\subsection{Glass Ionomer Cement}

Glass ionomer cement (GIC) is well known for its long history of usage in clinical dentistry ever since it was introduced by Wilson and Kent in 1971 [1]. GIC belongs to the acid-base cement class and has been a major restorative filling material used in atraumatic restorative treatment (ART) [2]. Atraumatic restorative treatment is a minimally invasive technique that is utilized in poorly compliant patients. In addition to functioning as a restorative material, GIC is also used in liners and bases, luting agents, fissure sealants as well as as an adhesive of orthodontic brackets [3].

GIC is composed of polymeric acid, ion-leachable glass, and water. These components mixture undergo a reaction setting, in which the acid will be neutralized by the basic glass powder [4]. According to Sidhu et al. [5], polyalkenoic acids are used as polymers in the synthesis of GIC. Two types of polyalkenoic acids can be used, which are homopolymer polyacrylic acid or the $2 \%$ copolymer of acrylic acid and maleic acid. The synthesis of glass ionomer cement is well described in the literature [4].

The main contributing factor for the successful and effective use of GIC in clinical dentistry is due to the unique properties, which include great adhesion to tooth structure although they are exposed to the moist environment in the mouth and do not require extra provisions to exhibit consistent adhesion [6]. This adhesion property of GIC aids in filling up the marginal gaps of the interface that lies between the tooth and restoration. GIC has a low 
coefficient of thermal expansion that remains unaffected by any temperature changes [7]. GIC, as a restorative material, exhibits a fluoride ion release property, which prevents cavity progression, as reported by Gupta et al. [8]. GIC also has great biocompatibility with the tooth structure as it does not irritate the pulp tissue or possess any carcinogenic potential.

Although it is widely used as a restorative material, GIC exhibits some limitations that cause major drawbacks in clinical use. This includes low mechanical properties, which includes the low fracture strength that makes it prone to cracks [9]. GIC is a brittle material [10] and it is not able to cope with high stress, which eventually leads to rapid breakages. Based on the study by Arita et al. [11], GIC has low sensitivity to moisture and desiccation that make it sensitive to dehydration in its early setting process, which limits the use of GIC in high stress-bearing areas. These disadvantages of GIC can be minimized by the combination with additional additives. The earliest attempt of incorporating additives into GIC was made by Simmons in 1983 [12] where silver amalgam alloy powder was added into GIC [13]. However, this modification was not adequate to improve GIC's properties. Cho et al. [14] incorporated resin into GIC and reported that resin-modified GIC has low sensitivity towards moisture compared to the conventional GIC. Since then, many attempts have been made to improve GIC's properties using other fillers, such as hydroxyapatite. A study by Yap et al. in 2002 [15] reported that the incorporation of hydroxyapatite particles into GIC was able to enhance the hardness of GIC. Lucas et al. [16] studied the mechanical properties of hydroxyapatite incorporated GIC, which concluded that the addition of hydroxyapatite has increased the fracture toughness and long-term bonding to dentin.

\subsection{Hydroxyapatite}

Hydroxyapatite is a major biologically active calcium phosphate ceramic, represented by a formula of $\left(\mathrm{Ca}_{10}\left(\mathrm{PO}_{4}\right)_{6}(\mathrm{OH})_{2}\right)$. Hydroxyapatite belongs to the apatite family which comprises of calcium and phosphates [17]. Hydroxyapatite can be naturally extracted from biological sources, including mammalian bones (e.g., pig bones) [18], eggshells and aquatic sources, such as fish bones and seashells [19], which is advantageous both environmentally and economically. The composition of hydroxyapatite mimics the inorganic fraction of mineralized tissues such as bones and teeth [20]. Thus, hydroxyapatite can be utilized as a coating on implants to induce bone growth into prosthetic implants and also can be used as a filling material to substitute damaged bones [21]. Apart from similar composition and chemical structure to bone phosphates, hydroxyapatite is also the most stable derivative of calcium phosphate salts at room temperature [22]. Hydroxyapatite has excellent biocompatibility in hard tissues, where it exhibits low cytotoxic effects [23], thus causing less harm to the pulp tissue. Hydroxyapatite can support the attachment, viability, and differentiation of osteoblastic cells [24]. Hydroxyapatite also has high solubility [25] that enables hydroxyapatite to efficiently fill the microspores in enamel by releasing inorganic ions. However, hydroxyapatite also shows some limitations. Calcium phosphate-based materials such as hydroxyapatite are brittle and they possess poor resistance to fatigue, thus limiting their usage as load bearing bioceramics [26]. Hydroxyapatite also exhibits low degradation rates, which makes the resorption of hydroxyapatite particles in the physiological environment difficult. Thus, a low degradation rate limits the use of hydroxyapatite as bone grafts, tissue engineering scaffolds and drug carriers [27].

Hydroxyapatite can be synthesized in many forms, such as dense ceramics, powder [28], and ceramics coating based on its specific applications. In recent years, hydroxyapatite nanoparticles have attracted much interest in the nanotechnology field due to their purity, morphology, and stoichiometry [29]. A vast number of methods are available for the manufacturing of hydroxyapatite nanoparticles and these methods are well described in the literature [30]. 


\section{Incorporating Nanohydroxyapatite into Glass Ionomer Cement (GIC)}

\subsection{Incorporation Technique of Nanohydroxyapatite into Glass Ionomer Cement (GIC)}

In recent times, nanohydroxyapatite particles are popularly incorporated into GIC as an additive to improve the cement's properties. The nanohydroxyapatite particles are added into glass ionomer cement in powdered form. These powdered form nanoparticles can be synthesized using various techniques, such as the sol-gel method, precipitation method, hydrothermal method and solid-state reaction method [31]. In addition, GIC is prepared by mixing a basic glass powder with a water-soluble polymer (acidic) [4].

\subsubsection{Sol-Gel Method}

A powdered form of nanohydroxyapatite synthesized via sol-gel method can be incorporated into glass ionomer cement. Rahman et al. [30] prepared nanohydroxyapatite by mixing calcium hydroxide into distilled water until a suspension is formed. Then, phosphoric acid was added drop by drop to the suspension and the suspension was stirred to obtain a viscous sol for a duration of $48 \mathrm{~h}$. Once the sol was obtained, it was filtered, freeze dried and calcined at $600{ }^{\circ} \mathrm{C}$ for $1 \mathrm{~h}$. Shiekh et al. [31] mixed nanohydroxyapatite powder synthesized vis sol-gel method into a commercial glass ionomer powder. The powder mixture was then mixed with the liquid polyacid at a powder: liquid ratio of 1:1. Then, the cement mixture was covered with a moist gauze and left for $24 \mathrm{~h}$, allowing a complete setting reaction. Moshaverinia et al. [32] incorporated nanohydroxyapatite particles that were synthesized using the sol-gel method into commercialized GIC powder by replacing a portion of the glass powder with nHA powder before combining the polymeric liquid.

\subsubsection{Precipitation Method}

Precipitation method is the most used method to synthesize hydroxyapatite. This method involves a chemical reaction between diluted calcium hydroxide and orthophosphoric acid at $\mathrm{pH}$ 9. The first step in precipitation method involves the mixing of an anion solution (calcium source) with a cation solution (phosphorus solution). Then, the mixture undergoes nucleation, precipitation, filtration and calcination processes [33]. Barandehfard et al. [24] incorporated nanohydroxyapatite particles that are obtained via precipitation method into GIC by blending the nHA powder and glass ionomer powder for $30 \mathrm{~min}$. Then, a powder to liquid ratio of 2.71:1 was used to mix the liquid polyacid into the GIC-nHA powder. Once mixed, the cement mixture was transferred to cylindrical molds and were covered with PTFE tape and glass slides for $30 \mathrm{~min}$ to set completely.

\subsubsection{Hydrothermal Method}

Hydrothermal method can be defined as the reaction method in an aqueous media higher than the ambient pressure and temperature [34]. Bilic-Pricic et al. [35] incorporated hydroxyapatite derived from cuttlefish using hydrothermal technique into commercially available GIC. The hydroxyapatite obtained from cuttlefish bones were ground and sifted, which leaves the hydroxyapatite powder in a hexagonal column crystal aggregate form. Then, the hydroxyapatite powder and glass powder were mixed manually with a mortar and pestle for a duration of $20 \mathrm{~min}$. Once mixed, the powder was mixed with polyacid liquid via spatulation. The hydrothermal method enables the synthesis of a highly porous hydroxyapatite [36]. Mahmoud et al. [37] incorporated nanohydroxyapatite into GIC by mixing the hydrothermally derived nanohydroxyapatite powder with glass ionomer powder with a plastic spatula on a glass slab. Then, the powder mixture was mixed again by amalgamator for $10 \mathrm{~s}$ to allow even distribution of nanohydroxyapatite particles before the liquid polyacid is added to the powder mixture and later the cement mixture was transferred to a mold to set.

\subsubsection{Solid-State Reaction}

The solid state reaction method is a dry method to synthesize nanohydroxyapatite. This method involves a decomposition reaction of a mixed solid reactant through heating 
to yield new solids and gases [38]. Nanohydroxyapatite is synthesized via solid-state reaction by mixing calcium carbonate $\left(\mathrm{CaCO}_{3}\right)$ and calcium pyrophosphate $\left(\mathrm{Ca}_{2} \mathrm{P}_{2} \mathrm{O}_{7}\right)$ in acetane, calcined in vacuum and treated with heat with the presence of water vapor [39]. Solid-state reaction yields a well-crystallized and a stoichiometric hydroxyapatite [40]. Hapuhinna et al. [41] synthesized hydroxyapatite via solid-state sintering using Sri Lankan chloroapatite and calcium hydroxide and compared it with commercially available glass ionomer cement.

\subsection{Effects of Incorporating Nanohydroxyapatite into Glass Ionomer Cement (GIC) \\ 2.2.1. Mechanical Strength}

Glass ionomer cement (GIC) in general has poor mechanical properties, which includes low compressive strength, fracture strength, toughness and wear resistance [42]. To overcome these poor mechanical properties of GIC, Barandehfard et al. [24] incorporated nanohydroxyapatite into GIC. The nanohydroxyapatite-added GIC showed a statistically higher compressive strength of about 107-113.6 MPa compared to the GIC only sample. The compressive strength of GIC containing hydroxyapatite nanoparticles was improved because of the increase in crystalline with the presence of nanoceramics. A study by Yap et al. [15] revealed that GIC that contains 4\% hydroxyapatite displayed a higher compressive strength compared to the commercially available GIC with no additives. Lucas et al. [16] determined the fracture toughness of nanohydroxyapatite-added GIC based on the method shown in ASTM specification E-399-90. Half of the mixed cement were tested 15 min after mixing and the remaining cement samples were stored, first, at $37{ }^{\circ} \mathrm{C}$ for $50 \mathrm{~min}$, and later, in distilled water for $23 \mathrm{~h}$. The stored samples were subjected to a three-point bending test to determine the fracture toughness. The results revealed that nanohydroxyapatite-added GIC samples had a significantly higher fracture toughness compared to the control sample in both $15 \mathrm{~min}$ and $24 \mathrm{~h}$ of storage. Moheet et al. [43] studied the compressive strength of GIC added with nanohydroxyapatite-silica particles and reported that the addition of nanohydroxyapatite-silica particles into GIC has increased the compressive strength compared to the conventional GIC sample. This is because the nHA-silica particles fill the void spaces, thus preventing defects and pores to form cracks. GIC suffers from poor resistance to wear. Mahmoud et al. [37] evaluated the wear rate of GIC incorporated with nanohydroxyapatite after immersing the cement samples in artificial saliva. The results revealed that the addition of nanohydroxyapatite enhanced the wear resistance of GIC. Another study by Al-Hamaoy et al. [38] also revealed that the incorporation of nanohydroxyapatite and microhydroxyapatite increased the wear resistance of GIC.

\subsubsection{Flexural Strength}

Hydroxyapatite nanoparticles are added to the GIC to observe their effects against its flexural strength. Flexural strength is the ability of a material to resist deformation under load. Basir et al. [44] evaluated the flexural strength of GIC incorporated with hydroxyapatite nanoparticles, in which the cement samples (GIC only and nanohydroxyapatite added GIC) were clamped for 50 min at $37^{\circ} \mathrm{C}$ before being submerged in distilled water for $23 \mathrm{~h}$. Then, the samples were subjected to a three-point bending test at a crosshead speed of $0.5 \mathrm{~mm} / \mathrm{min}$. Based on the International Testing Standards (ISO), the three-point bending test is a primary test to evaluate the strength of polymer-based restorative materials. Basir et al. [44] reported that nanohydroxyapatite particles enhanced the GIC's flexural strength, thus, showing an increase in flexural strength compared to the control group, which is GIC only. Arita et al. [11] reported that the nanohydroxyapatite-added GIC sample had shown a significant increase in flexural strength compared to GIC only sample. Lucas et al. [16] concluded that hydroxyapatite may enhance the initial flexural strength of GIC in an aqueous environment without disrupting the GIC's long term maturation. Based on a study by Moheet et al. [43], the flexural strength of GIC showed a 53.34\% increase with the 
addition of $10 \%$ nanohydroxyapatite. The porosity of hydroxyapatite enhances the flexural strength of GIC without changing its properties [40].

\subsubsection{Microhardness}

Microhardness is a vital property of dental materials. Microhardness can be described as the ability of the material to resist plastic deformation [41]. Fillers, such as nanohydroxyapatite can be added to GIC to enhance the microhardness property. Barandehfard et al. [24] evaluated the microhardness of glass ionomer cement added with nanohydroxyapatite by storing the cement samples in distilled water at $37^{\circ} \mathrm{C}$ for 1 and 7 days. The results revealed that the microhardness of nanohydroxyapatite added GIC was doubled after day 7 compared to GIC only sample. Al-Hamaoy et al. [38] studied the surface microhardness of GIC by adding micro and nanohydroxyapatite particles using a $Q$ time digital microhardness tester. The results concluded that the addition of nanohydroxyapatite enhanced the microhardness of GIC compared to microhydroxyapatite. Microhardness of GIC reinforced with nanohydroxyapatite was studied by Masaeli et al. [37] using a Long-term Vickers microhardness test at time points of $1 \mathrm{~h}, 24 \mathrm{~h}, 1,2,3$ and 11 weeks. Based on the results, GIC added with nanohydroxyapatite showed a decrease in microhardness compared to the GIC only samples. This decrease in microhardness might be due to the aggregation of nanoparticles as the agglomeration of nanoparticles may prevent these particles from interacting with the polyacid [42].

\subsubsection{Cytotoxicity}

As a restorative material, GIC should be biocompatible, where it should not pose any harm to the dental pulp tissue as it is placed close to the dental pulp. If the GIC is not compatible, substances from the cement can leach out, causing harm to the dental pulp tissue [45] due to the cytotoxicity. In order to reduce cytotoxicity, nanohydroxyapatite particles are incorporated into the GIC to improve their biocompatibility. Noorani et al. [46] evaluated the cytotoxicity of GIC added with nanohydroxyapatite-silica on Dental Pulp Stem Cells (DPSC) using the MTT Assay. MTT Assay is a quantitative, sensitive and reliable colorimetric in vitro assay that evaluates cells viability and proliferation [45]. GIC incorporated with nanohydroxyapatite-silica particles showed increased cell viability compared to the conventional GIC [45]. Pagano et al. [47] extensively studied the cytotoxic properties of GIC on human gingival fibroblasts and human keratinocyte cells by incorporating $4 \%$ nanohydroxyapatite into GIC. Based on their study, cytotoxicity was significantly reduced in the GIC sample that was added with $4 \%$ nanohydroxyapatite compared to the GIC sample with no addition of nanohydroxyapatite. The low cytotoxicity exhibited by $4 \%$ nanohydroxyapatite-added GIC is due to the chemical composition and crystalline structure of nanohydroxyapatite that is identical to the apatite structure in humans [47].

\subsubsection{Microleakage}

Microleakage is one of the major contributing factors of failure in the usage of GIC as it causes secondary caries and irritation to the pulp tissue [48]. Mu et al. [49] studied the microleakage property of GIC that is incorporated with nanohydroxyapatite. Two groups of samples were used, which were GIC added with $8 \%$ nanohydroxyapatite and GIC only samples. The microleakage property was measured at the composite-dentine interface on the prepared class V cavities. The result showed that the GIC added with nanohydroxyapatite demonstrated minimal microleakages compared to the GIC only group. New nanohydroxyapatite crystals were formed into a new mineralizing zone at the GIC added with nanohydroxyapatite, whereas, no hydroxyapatite crystals were formed in GIC only sample [49]. Enan et al. [50] evaluated the microleakage property of GIC added with nanohydroxyapatite under orthodontic bands. The microleakage property was evaluated at the cement-band and cement-enamel interfaces using the dye penetration method. The dye penetration method is commonly used to evaluate the microleakage property, as it is inexpensive and relatively easy to perform [51]. The results showed that the GIC added 
with $15 \%$ nanohydroxyapatite showed lower microleakage scores compared to the GIC-only sample. It was also reported that the addition of nanohydroxyapatite into the GIC exerted fewer microleakages around orthodontic bands compared to the conventional GIC sample. This lower microleakage property is due to the strong hydrogen and ionic bonds caused by the ions released from the acid-base reaction between the GIC and hydroxyapatite [50].

\subsubsection{Fluoride Ion Release}

The fluoride ion release property of GIC is crucial to prevent the incidence of dental caries by bacterial growth inhibition [52]. The fluoride release in GIC lasts up to 18 months in diminishing amounts [15]. Alatawi et al. [53], evaluated the concentration of fluoride ion release in nanohydroxyapatite-added GIC and conventional GIC-only samples. The concentration of fluoride ion release was measured at 24 h, 48 h, 72 h, 7 days, 14 days and 28 days intervals using an ion selective electrode [54]. It was reported that the samples added with nanohydroxyapatite demonstrated an increase in fluoride ion release compared to the conventional GIC without nanohydroxyapatite addition. The fluoride ion release value of nanohydroxyapatite-added GIC was directly proportional to the nanohydroxyapatite $\mathrm{w} t \%$. This is due to the larger surface area of nanohydroxyapatite particles that contributed to the increased acid-base reactivity, thus, increasing the fluoride ion release [55]. In another study by Moheet et al. [56], fluoride ion release of GIC added with nanohydroxyapatite-silica was evaluated. The fluoride ion release was measured using the fluoride ion selective electrode method. The results showed that the sample of GIC added with nanohydroxyapatite-silica had increased fluoride ion release compared to the conventional GIC samples. Moshaverinia et al. [32] reported that the addition of hydroxyapatite into GIC demonstrated a higher fluoride release compared to the conventional GIC.

\subsubsection{Antibacterial Properties}

Bacteria present in the oral cavity plays a key role in the occurrence of dental caries [57]. Several studies have discovered that high amounts of Streptococcus mutans bacteria is directly related to an increase in the rate of dental caries [58]. Thus, the GIC must possess a great antibacterial property to prevent the occurrence of dental caries and to retain a long-term restoration [59]. Alatawi et al. [53] evaluated the antibacterial property of GIC that is added with different weight percentages of nanohydroxyapatite using a disk diffusion test. The antibacterial activity is measured based on the size of the inhibition zone formed around the cement samples. It was reported that the antibacterial activity of GIC is enhanced when the weight percentage of nanohydroxyapatite is increased up to $10 \%$ with an inhibition zone size of $8.6 \mathrm{~mm}$ compared to the conventional GIC sample [53]. The formation of inhibition zones around the cement samples is because of the nanoparticles entering the bacterial cell and inducing oxidative stress, which in turn, inhibits the growth and causes bacterial cell death [60]. Another study on the antibacterial property of porous hydroxyapatite incorporated GIC was carried out by Shinonaga et al. [61] using the Adenosine triphosphate (ATP) luminescence method, which is a rapid, easy to perform and sensitive assay [62]. It was reported that the addition of hydroxyapatite increased the antibacterial property of the nanohydroxyapatite-added GIC compared to the conventional GIC sample. Pagano et al. [47] incorporated 4\% nanohydroxyapatite into GIC and reported that the addition of $4 \%$ nanohydroxyapatite enhanced the antibacterial activity of GIC against $S$. mutans bacteria.

\section{Conclusions}

As a widely used restorative material in clinical dentistry, GIC exhibits great advantages, such as biocompatibility, fluoride ion release, chemical bonding to the tooth surface and low coefficient in the thermal expansion. Despite having such advantages, GIC exerts some shortcomings which limit its usage in clinical dentistry, particularly in high-stress bearing areas. The shortcomings of GIC can be improved by the addition of specific additives. Nanohydroxyapatite, which is a biologically active phosphate ceramic, is one 
of the common additives that is being used in GIC. The incorporation of nanohydroxyapatite into GIC showed favorable improvements in the mechanical properties, flexural strength, antibacterial properties, and fluoride ion release as well as reducing the microleakage and cytotoxic properties of the GIC. The incorporation of nanohydroxyapatite into GIC has shown great improvements in the physical and biological properties of the GIC, thus, making it one of the most suitable additives to be used (Table 1). The addition of nanohydroxyapatite into GIC can be beneficial to restorative applications, particularly, at high-stress bearing areas, replacing the existing commercial GIC. Further studies should be done on the biological properties of GIC incorporated with nanohydroxyapatite as there are not many studies regarding this property. Other additives could be used to explore other potential improvements in the GIC properties.

Table 1. Effects of Hydroxyapatite Incorporation into GIC.

\begin{tabular}{|c|c|c|c|c|}
\hline Type/Composition of GIC & Type of HA Used & Analysis & Outcomes & Reference \\
\hline $\begin{array}{c}\text { Fuji I GC } \\
\text { Fluoroalumino-silicate glass } \\
\text { powder and liquid PAA }\end{array}$ & NanoHA & $\begin{array}{l}\text { Flexural strength } \\
\text { Shear bond strength }\end{array}$ & $\begin{array}{l}6 \% \text { nanoHA enhanced both } \\
\text { flexural strength and shear } \\
\text { bond strength }\end{array}$ & [63] \\
\hline $\begin{array}{c}\text { Conventional GIC } \\
\text { Fluoroalumino-silicate glass } \\
\text { powder, acrylic and maleic } \\
\text { acid polybase carboxylic } \\
\text { acid, water }\end{array}$ & ZnO- nanoHA & $\begin{array}{l}\text { Antimicrobial properties } \\
\text { using disk diffusion test. } \\
\text { Microhardness testing } \\
\text { using Vickers hardness } \\
\text { indentation test. }\end{array}$ & $\begin{array}{l}\text { ZnO-nHA improved the } \\
\text { antimicrobial activity of GIC } \\
\text { against S.mutans and E.coli. } \\
\text { The microhardness of GIC is } \\
\text { increased by the addition } \\
\text { of ZnO-nHA. }\end{array}$ & {$[60]$} \\
\hline $\begin{array}{l}\text { Fuji III } \\
\text { Fluoroalumino-silicate } \\
\text { powder, liquid PAA } \\
\text { and water. }\end{array}$ & $\begin{array}{l}\text { Porous hydroxyapatite } \\
\text { (HA) }\end{array}$ & $\begin{array}{l}\text { Flexural strength via } \\
\text { three point bending test. } \\
\text { Antibacterial activity } \\
\text { using ATP } \\
\text { luminescence method. } \\
\text { Fluoride ion release test. }\end{array}$ & $\begin{array}{c}\text { Flexural strength } \\
\text { significantly increased when } \\
28 \% \text { HA is added. } \\
\text { Addition of HA increased } \\
\text { the antibacterial activity and } \\
\text { fluoride ion release. }\end{array}$ & {$[61]$} \\
\hline $\begin{array}{c}\text { Fuji II LC } \\
\text { Fluoro-alumino-silicate } \\
\text { glass powder, liquid PAA, } \\
\text { distilled water, 2-HEMA, } \\
\text { urethane dimethylacrylate, } \\
\text { camphorquinone. }\end{array}$ & nanoHA & $\begin{array}{l}\text { Flexural strength. } \\
\text { Compressive strength. }\end{array}$ & $\begin{array}{c}8 \% \text { nHA addition increased } \\
\text { flexural and } \\
\text { compressive strength. }\end{array}$ & [49] \\
\hline $\begin{array}{c}\text { Resin-modified GIC } \\
\text { (RMGIC) } \\
\text { Aluminosilicate glass } \\
\text { powder, liquid PAA, } \\
\text { distilled water, HEMA, } \\
\text { dimethacrylate monomer } \\
\text { and camphorquinone. }\end{array}$ & NanoHA & $\begin{array}{l}\text { Cytotoxicity test using } \\
\text { MTT assay. }\end{array}$ & $\begin{array}{l}\text { Cell viability increased when } \\
\text { nHA is increased up to } 10 \%\end{array}$ & {$[64]$} \\
\hline
\end{tabular}

Abbreviation: HEMA—hydroxyethylmethacrylate, PAA—polyacrylic acid.

Author Contributions: Initial planning: R.M. and N.N.M.A.; Literature search and initial drafting: R.M.; Text revision: N.N.M.A., F.Y. and N.S.N. All authors have read and agreed to the published version of the manuscript.

Funding: This research was funded by the Fundamenbtal Research Grant Scheme (FRGS), Ministry of Higher Education, Malaysia (FRGS/1/2020/SKK0/UKM/03/4).

Data Availability Statement: All data used and analyzed for the current study are available from the corresponding author on reasonable request.

Conflicts of Interest: The authors declare no conflict of interest. 


\section{References}

1. Croll, T.P.; Nicholson, J.W. Glass ionomer cements in pediatric dentistry: Review of the literature. Pediatric Dent. 2002, 24, 423-429.

2. Da Silva, R.C.; Cilense, Z.C. Surface roughness of glass ionomer cements indicated for atrumatic restorative treatment (ART). Braz. Dent. J. 2006, 17, 106-109. [CrossRef] [PubMed]

3. Berg, J.H.; Croll, T.P. Glass ionomer restorative cement systems: An update. Pediatric Dent. 2015, 37, $116-124$.

4. Nagaraja Upadhya, P.; Kishore, G. Glass ionomer cement-The different generations. Trends Biomater. Artif. Organs 2005, 18, 158-165.

5. Sidhu, S.; Nicholson, J. A Review of Glass-Ionomer Cements for Clinical Dentistry. J. Funct. Biomater. 2016, 7, 16. [CrossRef]

6. Davidson, C.L. Advances in glass-ionomer cements. J. Appl. Oral Sci. 2006, 14, 3-9. [CrossRef]

7. Alobiedy, A.N.; Al-Helli, A.H.; Al-Hamaoy, A.R. Effect of adding micro and nano-carbon particles on conventional glass ionomer cement mechanical properties. Ain Shams Eng. J. 2019, 10, 785-789. [CrossRef]

8. Gupta, A.A.; Mulay, S.; Mahajan, P.; Raj, A.T. Assessing the effect of ceramic additives on the physical, rheological and mechanical properties of conventional glass ionomer luting cement-An in-vitro study. Heliyon 2019, 5, e02094. [CrossRef] [PubMed]

9. Garoushi, S.; He, J.; Vallittu, P.K.; Lasilla, L.V. Effect of discontinuous glass fibers on mechanical properties of glass ionomer cement. Acta Biomater. 2018, 4, 72-80. [CrossRef] [PubMed]

10. Mustafa, H.A.; Soares, A.P.; Paris, S.; Elhennawy, K.; Zaslansky, P. The forgotten merits of GIC restorations: A systematic review. Clin. Oral Investig. 2020, 24, 2189-2201. [CrossRef]

11. Arita, K.; Yamamoto, A.; Shinonaga, Y.; Harada, K.; Abe, Y.; Nakagawa, K.; Sugiyama, S. Hydroxyapatite particle characteristics influence the enhancement of the mechanical and chemical properties of conventional restorative glass ionomer cement. Dent. Mater. J. 2011, 30, 672-683. [CrossRef]

12. Simmons, J.J. The miracle mixture. Glass ionomer and alloy powder. Tex. Dent. J. 1983, 100, 6-12.

13. Sajjad, A.; Bakar, W.Z.W.; Mohamad, D.; Kannan, T.P. Characterization and Enhancement. Physico-Mechanical Properties Glass Ionomer Cement by Incorportaing A Novel Nano Zirconia Silica Hydroxyapatite Synthesized via Sol-Gel. AIMS Mater. Sci. 2019, 6, 730-747. [CrossRef]

14. Cho, E.; Kopel, H.; White, S.N. Moisture susceptibility of resin-modified glass ionomer materials. Quintessence Int. 1995, 26, 351-358.

15. Yap, A.; Cheang, P.; Chay, P. Mechanical properties of two restorative reinforced glass-ionomer cements. J. Oral Rehabil. 2002, 29, 682-688. [CrossRef]

16. Lucas, M.E.; Arita, K.; Nishino, M. Toughness, bonding and fluoride-release properties of hydroxyapatite-added glass ionomer cement. Biomaterials 2003, 24, 3787-3794. [CrossRef]

17. Haider, A.; Haider, S.; Han, S.S.; Kang, I.-K. Recent advances in the synthesis, functionalization and biomedical applications of hydroxyapatite: A review. Rsc Adv. 2017, 7, 7442-7458. [CrossRef]

18. Xiaoying, L.; Yongbin, F.; Wei, C. Preparation and characterization of natural hydroxyapatite from animal hard tissues. Key Eng. Mater. 2007, 342, 213-216.

19. Pu'ad, N.A.M.; Koshy, P.; Abdullah, H.; Idris, M.; Lee, T. Syntheses of hydroxyapatite from natural sources. Heliyon 2019, 5, e01588.

20. Dorozhkin, S. Calcium orthophosphates in nature, biology and medicine. Materials 2009, 2, 399-498. [CrossRef]

21. Akram, M.; Ahmed, R.; Shakir, I. Extracting hydroxyapatite and its precursors from natural resources. J. Mater. Sci. 2014, 49, 1461-1475. [CrossRef]

22. Mobasherpour, I.; Heshajin, M.S.; Kazemzadeh, A.; Zakeri, M. Synthesis of nanocrystalline hydroxyapatite by using precipitation method. J. Alloys Compd. 2007, 430, 330-333. [CrossRef]

23. Wahab, R.M.A.; Abdullah, N.; Ariffin, S.H.Z.; Abdullah, C.A.C.; Yazid, F. Effects of the Sintering Process on Nacre-Derived Hydroxyapatite Scaffolds for Bone Engineering. Molecules 2020, 25, 3129. [CrossRef] [PubMed]

24. Barandehfard, F.; Rad, M.K.; Hosseinnia, A.; Khoshroo, K.; Tahriri, M.; Jazayeri, H.E.; Moharamzadeh, K.; Tayebi, L. The addition of synthesized hydroxyapatite and fluorapatite nanoparticles to a glass-ionomer cement for dental restoration and its effects on mechanical properties. Ceram. Int. 2016, 42, 17866-17875. [CrossRef]

25. Lin, K.; Chang, J. Structure and properties of hydroxyapatite for biomedical applications. In Hydroxyapatite (HAp) for Biomedical Applications; Woodhead Publishing: Oxford, UK, 2015; pp. 3-9.

26. Prakasam, M.; Locs, J.; Ancane, K.S.; Loca, D.; Largeteau, A.; Berzina-Cimdina, L. Fabrication, properties and applications of dense hydroxyapatite: A review. J. Funct. Biomater. 2015, 6, 1099-1140. [CrossRef]

27. Kong, L.B.; Ma, J.; Boey, F. Nanosized hydroxyapatite powders derived from coprecipitation process. J. Mater. Sci. 2002, 37, 1131-1134. [CrossRef]

28. Kantharia, N.; Naik, S.; Apte, S.; Kheur, M.; Kheur, S.; Kale, B. Nano-hydroxyapatite and its contemporary applications. Bone 2017, 34, 1-71. [CrossRef]

29. Amit, K.N. Hydroxyapatite synthesis methodologies: An overview. Int. J. ChemTech Res. 2010, 2, $903-907$.

30. Rahman, I.A.; Masudi, S.M.; Luddin, N.; Rayees, A.S. One-pot synthesis of hydroxyapatite-silica nanopowder composite for hardness enhancement of glass ionomer cement (GIC). Bull. Mater. Sci. 2014, 37, 213-219. [CrossRef]

31. Shiekh, R.A.; Rahman, I.A.; Masudi, S.M.; Luddin, N. Modification of glass ionomer cement by incorporating hydroxyapatite-silica nano-powder composite: Sol-gel synthesis and characterization. Ceram. Int. 2013, 40, 3165-3170. [CrossRef] 
32. Moshaverinia, A.; Ansari, S.; Moshaverinia, M.; Roohpour, N.; Darr, J.A.; Rehman, I. Effects of incorporation of hydroxyapatite and fluoroapatite nanobioceramics into conventional glass ionomer cements (GIC). Acta Biomater. 2008, 4, 432-440. [CrossRef]

33. Anitha, P.; Pandya, H.M. Comprehensive review of preparation methodologies of nanohydroxyapatite. J. Environ. Nanotechnol. 2014, 3, 101-121.

34. Huang, G.; Lu, C.-H.; Yang, H.-H. Magnetic nanomaterials for magnetic bioanalysis. Nov. Nanomater. Biomed. Environ. Energy Appl. 2019, 89, 109.

35. Bilic-Pricic, M.; Rajic, V.B.; Ivanisevic, A.; Pilipovic, A.; Gurgan, S.; Miletic, I. Mechanical properties of glass ionomer cements after incorporation of Marine Derived Hydroxyapatite. Materials 2020, 13, 3542. [CrossRef]

36. Rogina, A.; Antunovic, M.; Milovac, D. Biomimetic design of bone substitutes based on cuttlefish bone-derived hydroxyapatite and biodegradable polymers. Biomed. Mater. Res. B Appl. Biomater. 2019, 107, 197-204. [CrossRef] [PubMed]

37. Mahmoud, N.A.; Metwally, A.A. Fluoride release and recharging ability of glass ionomer cement incorporating hydroxyapatite nanoparticles. Egypt. Dent. J. 2021, 67, 3741-3749. [CrossRef]

38. Al-Hamaoy, A.R.; Alobiedy, A.N.; Alhille, A.H. Glass ionomer cement mechanical properties enhancement using hydroxyapatite micro and nano particles. ARPN J. Eng. Appl. Sci. 2018, 13, 2090-2095.

39. Rhee, S.-H. Synthesis of hydroxyapatite via mechanochemical treatment. Biomaterials 2002, 23, 1147-1152. [CrossRef]

40. Lin, K.; Chang, J.; Cheng, R.; Ruan, M. Hydrothermal microemulsion synthesis of stoichiometric single crystal hydroxyapatite nanorods with mono-dispersion and narrow-size distribution. Mater. Lett. 2007, 61, 1683-1687. [CrossRef]

41. Hapuhinna, H.K.G.K.D.; Gunaratne, R.; Pitawala, H.M.J. A novel approach of synthesizing 2-hydroxyethyl methacrylate embedded hydroxyapatite composites for dentistry applications. R. D. Gunaratne J. Eng. Res. Appl. 2019, 9, 51-57.

42. Rahman, N.A.A.; Matori, K.; Zaid, M.; Zainuddin, N.; Aziz, S.A.; Khiri, M.Z.A.; Jalil, R.A.; Jusoh, W.N.W. Fabrication of Alumino-Silicate-Fluoride based bioglass derived from waste clam shell and soda lime silica glasses. Results Phys. 2019, 12, 743-747. [CrossRef]

43. Moheet, I.A.; Luddin, N.; Rahman, I.A.; Masudi, S.M.; Kannan, T.P.; Ghani, N.R.N.A. Evaluation of mechanical properties and bond strength of nano-hydroxyapatite-silica added glass ionomer cement. Ceram. Int. 2018, 44, 9899-9906. [CrossRef]

44. Basir, M.M.; Ataei, M.; Rezvani, M. The effect of different amounts of hydroxyapatite nanoparticles on the mechanical properties of resin modified glass ionomer. J. Dent. Sch. 2011, 30, 216-223.

45. Masaeli, R.; Ketabat, F.; Zandsalimi, K. Microhardness and wear resistance of glass ionomer cements modified by chitosan anf nano-hydroxyapatite. J. Dentomaxillofacial 2019, 8, 8-13.

46. Noorani, T.Y.; Norhayati, L.; Rahman, I.A.; Masudi, S.M. In vitro Cytotoxicity Evaluation of Novel Nano-Hydroxyapatite-Silica Incorporated Glass Ionomer Cement. J. Clin. Diagn. Res. 2017, 11, ZC105. [CrossRef]

47. Pagano, S.; Chieruzzi, M.; Balloni, S.; Lombardo, G.; Torre, L.; Bodo, M.; Cianetti, S.; Marinucci, L. Biological, thermal and mechanical characterization of modified glass ionomer cements: The role of nanohydroxyapatite, ciprofloxacin and zinc Lcarnosine. Mater. Sci. Eng. C 2019, 94, 76-85. [CrossRef] [PubMed]

48. De Castro, A.K.B.B.; Pimenta, L.A.F.; Amaral, C.M.; Ambrosano, G.M.B. Evaluation of microleakage in cervical margins of various posterior restorative systems. J. Esthet. Restor. Dent. 2002, 14, 107-114. [CrossRef]

49. Mu, Y.; Zang, X.; Sun, H.; Wang, C. Effect of nano-hydroxyapatite to glass ionomer cement. West China J. Stomatol. 2007, 25, 544-547.

50. Enan, E.T.; Hammad, S.M. Microleakage under orthodontic bands cemented with nano-hydroxyapatite- modified glass ionomer An in vivo study. Angle Orthod. 2013, 83, 981-986. [CrossRef] [PubMed]

51. Nishimura, T.; Shinonaga, Y.; Abe, Y.; Kawai, S.; Arita, K. Porous hydroxyapatite can improve strength and bioactive functions of glass ionomer cement. Nano Biomed. 2014, 6, 53-62.

52. Selimovic-Dragas, M.; Lajla, H.-B.; Huseinbegovic, A.; Kobaslija, S.; Lekic, M.; Hatibovic-Kofman, S. In vitro fluoride release from a different kind of conventional and resin modified glass-ionomer cements. Bosn. J. Basic Med. Sci. 2013, 13, 197. [CrossRef] [PubMed]

53. Alatawi, R.A.S.; Elsayed, N.H.; Mohamed, W.S. Influence of hydroxyapatite nanoparticles on the properties of glass ionomer cement. J. Mater. Res. Technol. 2019, 8, 344-349. [CrossRef]

54. Hoszek, A.; Ericson, D. In vitro fluoride release and the antibacterial effect of glass lonomers containing chlorhexidine gluconate. Oper. Dent. 2008, 33, 696-701. [CrossRef]

55. Attar, N.; Önen, A. Fluoride release and uptake characteristics of aesthetic restorative materials. J. Oral Rehabil. 2002, 29, 791-798. [CrossRef]

56. Moheet, I.A.; Luddin, N.; Rahman, I.A.; Masudi, S.M.; Kannan, T.P.; Ghani, N.R.N.A. Novel nano-hydroxyapatite-silica-added glass ionomer cement for dental application: Evaluation of surface roughness and sol-sorption. Polym. Polym. Compos. 2020, 28, 299-308. [CrossRef]

57. Chen, C.N.; Huang, G.F.; Guo, M.K.; Lin, C.P. An in vitro study on restoring bond strength of a GIC to saliva contaminated enamel under unrinse condition. J. Dent. 2002, 30, 189-194. [CrossRef]

58. Vega-Avila, E.; Pugsley, M. An overview of colorimetric assay methods used to assess survival or proliferation of mammalian cells. Proc. West. Pharmacol. Soc. 2011, 54, 10-14. [PubMed] 
59. Hafshejani, T.M.; Zamanian, A.; Reddy, V.J.; Zahra, R.; Sefat, F.; Mohammad, R.S.; Vahabi, H.; Zarrintaj, P. Mozafari Antibacterial glass-ionomer cement restorative materials: A critical review on the current status of extended release formulations. J. Control Release 2017, 26, 317-328. [CrossRef]

60. Gupta, A.; Singh, D.; Raj, P.; Gupta, H.; Verma, S.; Bhattacharya, S. Investigaton of ZnO-hydroxyapatite nanocomposite incorporated in restorative glass ionomer cement to enhance its mechanical and antibacterial properties. J. Bionanoscience 2015, 9 , 190-196. [CrossRef]

61. Shinonaga, Y.; Arita, K.; Nishimura, T.; Chiu, S.Y.; Chiu, H.H.; Abe, Y.; Sonomoto, M.; Harada, K.; Nagaoka, M. Effects of porous-hydroxyapatite incorporated into glass-ionomer sealants. Dent. Mater. J. 2015, 34, 196-202. [CrossRef]

62. Guan, X.; Zhang, H.; Bi, Y.; Zhang, L.; Hao, D.-L. Rapid detection of pathogens using antibody-coated microbeads with bioluminescence in microfluidic chips. Biomed. Microdevices 2010, 12, 683-691. [CrossRef] [PubMed]

63. Kheur, M.; Kantharia, N.; Lakha, T.; Kheur, S.; Husain, N.A.-H.; Ozcan, M. Evaluation of mechanical and adhesion properties of glass ionomer cement incorporating nano-sized hydroxyapatite particles. Odontology 2020, 108, 66-73. [CrossRef] [PubMed]

64. Genaro, L.E.; Anovazzi, G.; Hebling, J.; Zuanon, A.C.C. Glass ionomer cement modified by resin with incorporation of nanohydroxyapatite: In vitro evaluation of physical-biological properties. Nanomaterials 2020, 10, 1412. [CrossRef] [PubMed] 